\title{
Writing with Conviction: The Use of Boosters in Modelling Persuasion in Academic Discourses
}

\author{
Ignacio Vázquez and Diana Giner \\ University of Zaragoza \\ ivazquez@unizar.es / dginer@unizar.es
}

\begin{abstract}
Hedging and boosting are significant communicative resources to construe and attain persuasion in different fields and particular genres of academic writing. They are both two sides of the same coin in the sense that they both contribute to the persuasive import of academic communication. Although boosting is a much less researched phenomenon than hedging, it is a key aspect of rhetorical persuasion in academic writing. This paper is devoted to the analysis of the use of boosters in a corpus of articles from three different disciplines (Marketing, Biology and Mechanical Engineering), and in this sense it is complementary to our previous article (Vázquez and Giner, 2008) in which we explored the use of epistemic markers used as hedges in the same corpus of RAs. Based on computer readable data, and combining quantitative and qualitative methods, the article argues that boosting deserves particular attention if we want to fully interpret the phenomenon of academic persuasion.
\end{abstract}

\section{Introduction}

Academic writing is normally based on empirical research, which is reported to the scientific community objectively, but with sufficient conviction. This implies a promotional role on the part of academic writers. In order to fulfil the competing demands of persuasion and objectivity in academic writing, complex linguistic manoeuvring is required, drawing on interpersonal as well as ideational resources. The interpersonal contribution to this strategy involves the creation of the writer as a persona that is a presentation of the writer himself in the text to place new scientific work into the existing body of research and to create a 
consensus between new research and potentially dissenting ideas. This can be achieved, for example, through the use of modality, first person pronouns and attribution (Myers, 1990). Other authors have widely discussed the persuasive function of metadiscourse (Mauranen, 1993; Hyland, 1998 and 2005: 63-71; Dafouz, 2003 and 2007) and some studies have been carried out to analyse how metadiscourse markers attain persuasion and how such persuasion is metadiscursively articulated (Dafouz, 2007).

In this paper we focus on the analysis of research articles (henceforth RAs) randomly selected from different disciplines (Marketing, Biology and Mechanical Engineering). Our main objective is to see to what extent boosters are used in these fields with a persuasive and intensifying value. We also intend to shed some light on the controversy about using interactional elements like these in academic writing. We wanted to select RAs from two disciplines that could be considered dramatically different in terms of the nature of their data of study (Marketing and Mechanical Engineering) and one that could be placed somewhere in the middle between them (Biology). The reason for this variety in the discipline selection lies upon the possibility that we may find considerable differences in the occurrence of boosters.

One of the main lines of research undertaken within the InterLAE project ${ }^{1}$ has been the exploration of the differences that may exist in the use of interpersonal rhetorical strategies by authors of RAs from different disciplines. The underlying assumption for this line of study is that, when drafting their research for publication authors must employ rhetorical resources to interact with their readers in ways that are consistent with the social rules and expectations, as well as with the particular epistemological norms and conventions governing the discipline. Our hypothesis is then that the existing differences among these areas in terms of their epistemology, i.e. the nature of their data and subject matter, their norms of enquire, the degree of consensus or their procedures for interpretation, as well as differences in their social interactions - their relative degree of solidarity and proximity, their mechanisms for obtaining recognition and their network density - crucially determine the ways authors use interpersonal rhetorical strategies.

This paper is structures as follows. In Section 2, we look at the state of the art on boosters as they are used by academic writers. In section 3 we refer to Hyland's model of metadiscourse in order to interpret the use of interactional elements, such as boosters and hedges in the group of research articles just mentioned, to later focus more specifically on the functions of boosters in academic writing. Section 4 describes the cross-disciplinary analysis carried out to end up with the conclusion in section 5 .

\section{An overview of boosting in academic writing}

Propositional meaning can be formulated with different degrees of strength, ranging from very weak, tentative statements to very strong, assertive statements. In this paper we focus on this particular part of the cline, that is, on those lexico-grammatical features in the text which contribute to stating conviction and certainty on the part of academic writers. According to Hyland, boosters (e.g. definitely ..., I am sure that ..., we firmly believe...) create an impression 
of certainty, conviction and assurance, and they can be used to instill trust and confidence in academic readers. Hedges (e.g. it would appear that..., there is a good reason to believe that ..., may be possible...), on the other hand, are used to withhold the writer's commitment in order to protect him or her from too strong assertions, which may later prove to have been made in error (Hyland, 1998b: 236-238). Hyland concludes that there needs to be a balance between these two metadiscourse markers of credibility. According to him, boosters or certainty markers "allow writers to project a credible image of authority, decisiveness, and conviction in their views", while hedges help them to "demonstrate personal honesty and integrity through willingness to address hard realities, albeit behind a shield of mitigation" (1998b: 238).

Regarding hedges and boosters, linguistic literature on these elements often considers the two concepts as closely related, sometimes even inseparable from each other (see e.g. Grabe and Kaplan, 1997: 155). In their taxonomy of metadiscourse markers, Crismore, Markkanen and Steffensen (1993: 47-52) place certainty markers, along with a closely related category of hedges, as a subcategory under interpersonal metadiscourse markers. They state that certainty markers deal with the same phenomena as hedges - the writer's degree of commitment to the truth of their statement - but at the other end of the spectrum, i.e. denoting the writer's full commitment to the proposition instead of lack of it. Grabe and Kaplan (1997: 155-160) also see emphatics, or linguistic signs of assertion and emphasis, as being on the same "semantic cline of evidentiality" as hedges but at the other extreme. However, Grabe and Kaplan (1997: 155) point out that sometimes the two notions are so close to each other (as in the case of the word just) that both concepts can be referred to by using the term evidentials.

Holmes (1982), on the other hand, uses the term boosters to refer to lexical items that the writer can use to show strong conviction for a statement. They strengthen the utterance's illocutionary force, which is the opposite of the effect of downtoners, the term Holmes uses for hedges. In other words, instead of indicating tentativeness or uncertainty, boosters signal the writer's or speaker's confidence regarding the plausibility of his or her utterance (Holmes, 1982: 18-20). Along the same lines, Hyland argues that boosters serve to strengthen propositions and show the writer's commitment to his or her statements (1998a: 353). He points out that although such assertion of the writer's conviction can be seen as leaving little room for the reader's own interpretations, boosters also offer writers a medium to engage with their readers and create interpersonal solidarity. Myers (1989: 6-7) considers such intensifying features in science articles as examples of positive politeness devices.

When reviewing research concerning hedges and boosters, it becomes apparent that the former has been studied more extensively than the latter, especially in academic writing (see e.g. Hyland, 1998a: 353; Vassileva, 2001: 85). Some studies have concentrated solely on hedging (Clemen, 1997; Crismore and Markkanen, 1997; Crismore and Vande Kopple, 1998; Crompton, 1997; Koutsantoni, 2006; Markkanen and Schröder, 1997; Myers, 1989; Varttala, 1999), whereas others have devoted some amount of attention to intensifiers besides hedging or other metadiscourse markers (Crismore and Farnsworth, 1990; Crismore, Markkanen and Steffensen, 1993; Dafouz-Milne, 2008; Grabe and Kaplan, 1997; Holmes, 1982; Hyland, 1998a, Hyland, 1998b, Hyland, 1998d, Hyland, 1999). It seems that only a few studies have actually concentrated on emphatics to a greater extent (e.g. Fuertes-Olivera et al., 2001; 
Vassileva, 2001). Many of the studies that include emphatics deal with persuasive texts, such as advertising (Fuertes-Olivera et al., 2001), or newspaper editorials (Dafouz-Milne, 2008), a fact which might have contributed to their scope.

As Vassileva (2001: 85) points out, the linguists' focus on hedges over boosters is somewhat surprising, as the two concepts seem to be equally interesting topics of research both in terms of theory and practice. In her study concentrating on the expressions of commitment (i.e. boosters) and detachment (i.e. hedges) in Bulgarian and English academic texts, Vassileva comes to the conclusion that considering the entire scale of certainty expressed in her corpus is vital for the correct interpretation of the study results (Vassileva 2001: 91-95). Her findings demonstrate that Bulgarian scholars writing in their native language maintain the same commitment/detachment level throughout their academic texts, whereas Bulgarians writing in English tend to use a considerable number of boosters in the discussion section and end up making rather careful, hedged claims in the conclusion. Native speakers of English, on the other hand, were observed to do the opposite, i.e. hedge their claims heavily in the discussion part of their articles while using more emphasizing expressions and appearing more confident in the concluding section of their texts (Vassileva 2001, 87-91).

\section{Hyland's Metadiscourse Model and persuasion}

In this paper we have adopted Hyland's view of metadiscourse, as "the cover term for the selfreflective expressions used to negotiate interactional meanings in a text, assisting the writer (or speaker) to express a viewpoint and engage with readers as members of a particular community" (Hyland, 2005:37). Since the purpose of this paper is mainly to analyse the ways in which some communicative acts are carried out in RAs belonging to different disciplines, Hyland's definition results particularly interesting for emphasizing the interpersonal function of language. In accordance, Hyland's classification of metadiscourse deals with the ways in which writers create different functions in their discourse. His model takes into consideration two dimensions of interaction: the interactive dimension and the interactional dimension. The first one is related to the way the writer or the speaker organizes the information presented according to the audience. That is, the way the information is disposed will depend on the knowledge of the reader, the genre, etc. The function of metadiscourse elements here is to shape the information in order to meet the expected needs of the audience. The interactional dimension is more related to the actual communicative functions that the author wishes to transmit the audience. In this dimension, the function of metadiscourse elements will generally consist in modulating certain statements and enhance others with the main purpose of defending the author's conclusions and convincing the audience of their truth. Among the interactional elements of metadiscourse we can find a sub-classification according to their specific function: hedges, boosters, attitude markers, self-mentions and engagement markers. Since this work is focusing on the presence of boosters, we will only dedicate some space to their definition and functions.

A major characteristic of academic discourse is the presence of elements whose purpose 
is to modulate assertions or to emphasize statements. This epistemic dimension of interactional elements allows researchers to, somehow, lead the readership to interpret the statements present in a research article in the way the author desires. The immediate consequence and purpose of this is to reach the final communicative purpose of text: to convince the readership of the consequences or findings resulting from the data analyzed by the author. The information given has been exposed taking into account two important aspects for the right guidance of the audience. On the one hand, the author will have put stress on the factors that influence the final conclusions. On the other hand, risky assertions will have been modulated appropriately.

\subsection{Boosters and persuasion}

Boosters are a very important phenomenon in the construction of rhetorical style. They constitute part of the rhetorical elements used by scholars in order to reach their communicative purpose. One of the main needs authors have in academic writing is trying to convince their readership of the truth-value of their propositions. More specifically, this happens when authors are introducing propositions dealing with "new knowledge". In these cases, the writer will usually unfold the information beginning with the knowledge both the audience and him/herself share; that is, propositions about "known information". Then, the writer will attach the propositions containing new information resulting in an enhancement of these latter propositions. The propositional information contained in a statement must be put under the spotlight so that a particular statement sounds convincing to the audience. For example, "X is an old star in the Solar System. In consequence, X is going to explode soon."

Boosters strongly help to achieve the important writers' need of convincing their readership of the truth in their propositions. They are mainly used whenever writers consider it is not too risky to include them in their propositions. In those cases, they will not contribute to the negation of these, but to their enhancement. As Mur states in her work, "writers may be categorical in their phrasing of propositional content when they believe readers have been led throughout the argument and have been convinced of it" (Mur, 2007: 355). Boosters' main functions will be related to persuading and convincing the audience with arguments generally backed up with data presented in the text. For example, the new propositional information drawn from those findings may be stressed with the help of linguistic elements such as "clear", "certainly" or "definite". As Hyland (1998b: 368) affirms, "Boosters are then rhetorical, persuasive strategies which function to mark, or rhetorically manipulate, consensual understandings based on shared community membership". For these reasons, we must consider boosters in our analysis of the interactional elements influencing in the interpretation of propositional information in academic writing.

For many years it has been assumed that elements contributing to manipulative or persuasive purposes of an author were not appropriate in academic writing. It was assumed that in this type of discourse only aseptic truths should be allowed. This position is defended by scholars such as Booth (1985), Bazerman (1984) or Bolsky (1988). However, the reality seems to be much more different to this description. Academic discourse makes use of this resource so as to show new pieces of information as true. As Koutsantoni (2004: 172) affirms, 
the use of boosters "can be motivated by epistemological reasons and be based on the results and findings themselves, and combined with social goals in scientific communities, such as gaining agreement and consensus by appealing to common knowledge and shared understandings". Consequently, authors make use of boosters in order to show their confidence in the truth of a particular proposition. The target of their use is mainly to affect the response of the readership to which the text is addressed and convince them of the conclusions drawn by the scholar(s).

\subsection{Hyland's view of persuasion in academic discourse}

Hyland points out the use of persuasion as an important characteristic of academic discourse from a rhetorical point of view. There is a strong belief that what academic discourse tries to demonstrate is absolute truth and empirical arguments that support it. As Hyland (1998: 73) states, "academic writing provides an objective description of what the natural and human world is actually like and this, in turn, serves to distinguish it from the socially contingent". An important factor when considering RAs is that there is a strong link connecting knowledge and the results originated in academic communities. The action produced through academic writing implies a social practice that shapes this kind of writing in each discipline.

Let us have a brief look at sciences. In general terms, hard sciences have the label of reliable because they seem to be involved with objective, empirically verifiable knowledge. These disciplines are usually regarded as unfailing mainly due to an analytical model that builds their empirical observations. The descriptions contained in them are the result of accurate calculations. In contrast, soft knowledge disciplines imply the use of less numerical evidence to prove their statements. Thus, the data result more varied and ambiguous. As a result, scientific papers reflect this subjectivity and are fairly likely to make use of persuasive statements, which may involve the use of boosters.

Nevertheless, anyone's description of reality is subject to the particular conditions of that individual or group of individuals. In this manner, writer's uncertainty of their statements is very much a plausible issue in hard sciences. As a matter of fact, scientific theories are constantly being reassessed. Human observations are influenced by external factors and do not reliably represent the surrounded world. Theories, in conclusion, should never be taken as absolute truths. Following with this grounded principle, scholars find the need to make use of persuasive devices in order to engage the audience and convince them of accurate representation of what is being stated. Academic texts, thus, perform accordingly and try to perform a persuasive communicative act. They could be regarded as conversations between individuals. Authors of academic texts state their premises and the audience interprets them understanding what is being said, including the persuasive statements contained in them. On the other hand, soft sciences are not very different from hard sciences. Sociologists, for example, make their interpretation of the world and, more specifically, of social relations. Because the data originated in this sort of sciences may not appear as numerical and accurate as in the hard sciences, it is often believed that the outcoming knowledge from their research is not as reliable. However, we must not forget that all outcoming results are subject to interpretation. In this way, we can consider academic writing as a social process where 
interaction with the audience plays a fundamental part.

The role of interaction in academic writing is essential for the function it performs when constructing new knowledge. If the new information presented by the author was not assimilated by the audience and understood as such, it would not contribute to the development of the discipline involved. In order to construct this knowledge, different devices come into play. Linguistic conventions and devices, among which boosters are included, appear in the discourse to convince the audience of the certainty of its statements. Therefore, the persuasive practice of sciences constructs academic knowledge or truth in a social context. Due to the fact that every claim is subject to the audience's interpretation, the writer will try to enhance his or her own viewpoints by framing his or her arguments with boosting devices. As Hyland (1998: 79) states, "persuasion therefore involves relating one's independent research to shared experience, collectively creating knowledge through interacting with one's peers".

\section{Cross-disciplinary analysis of boosters: a sample study of RAs in Marketing, Mechanical Engineering and Biology}

\subsection{Methods of analysis}

Academic writing is created by paying special attention to the specific constraints or conventions of different disciplines. These constraints condition the resources used by academic writers in their different disciplines. Scholars' work is reflected in academic discourse through a selection of linguistic elements; and this selection is made by following the conventions or rules of a particular discourse community. These conventions might ensure academic writers that their work will actually be recognized by readers and accepted by their colleagues in that discourse community. As Varttala (2001:248) states, "different disciplines may not be altogether uniform when it comes to frequency, forms, and variety of hedges". In this way, boosters in Medicine may not present the same occurrence as in Linguistics or Biology.

In this paper we selected RAs from two disciplines that could be considered dramatically different in terms of the nature of their data of study (Marketing and Mechanical Engineering) and one that could be placed somewhere in the middle between them (Biology). The reason for this variety in the discipline selection lies upon the possibility that we may find considerable differences in the occurrence of boosters. For the analysis we have selected the model of metadiscourse suggested by Hyland (2005). In this categorisation, Hyland distinguishes between interactive and interactional elements, being boosters under the second label. Here is a taxonomy of boosters made by Hyland (2005: 218):

Actually, always, believe, believed, believes, beyond doubt, certain, certainly, clear, clearly, conclusively, decidedly, definite, definitely, demonstrate, demonstrated, demonstrates, doubtless, establish, established, evident, evidently, find, finds, found, in fact, incontestable, incontrovertible, incontrovertibly, indeed, indisputable, indisputably, know, known, must 
(possibility), never, no doubt, obvious, obviously, of course, prove, proved, proves, realize, realized, realizes, really, show, showed, shown, shows, sure, surely, think, thinks, thought, truly, true, undeniable, undeniably, undisputedly, undoubtedly, without doubt.

Our hypothesis of study expected to find diverse rates of frequency and through digital tools we have been able to scan the corpus in search for these interactional elements. The results happened to confirm these differences in the occurrence of boosters. The examples shown in this paper are illustrative of the different approach taken in relation to the different nature of the data used in each of the three disciplines. Some of the boosters identified by Hyland in his model of metadiscourse (2005) have been spotted within the text of the RAs in order to instantiate these differences.

\subsection{General analysis of boosters in the RAs selected}

Figure 1 shows that the amounts of boosters differ much in each discipline. This may be due to different nature of the data of each discipline. Soft sciences should make a wider use of these interactional elements due to the uncertainty of the data handled in their analysis. On the other hand, hard sciences would not have such a strong need; however, it is obvious that they still play a role in the discourse of Mechanical Engineering. We will now analyse each interactional category in isolation. In order to obtain an even more detailed analysis, we will collect some samples in each discipline to observe more closely the effect of these elements upon the audience.

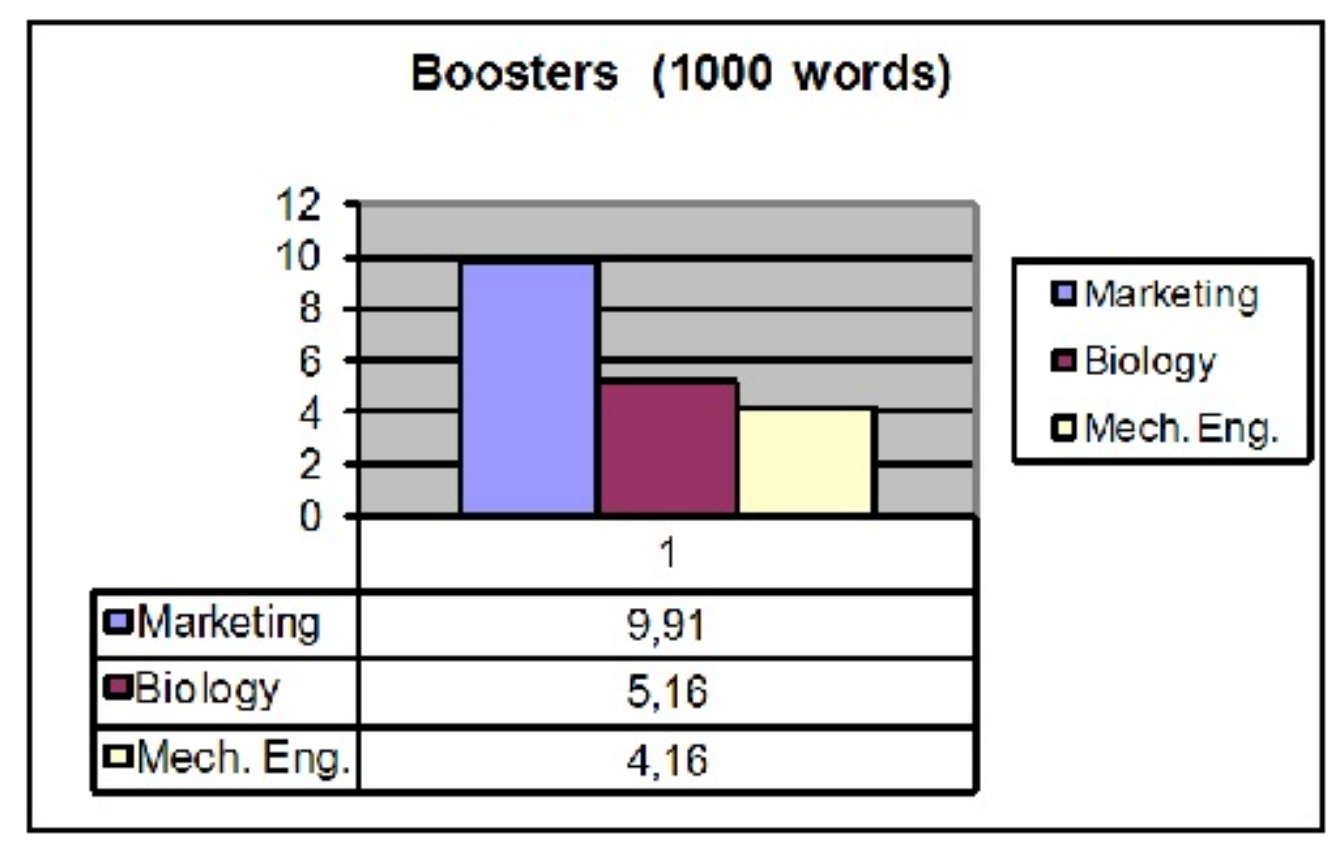

Figure 1: Frequency of boosters in RAs (Marketing, Biology and Mechanical Engineering). 
The results reveal that the total number of boosters per 1,000 words in the three disciplines indicates that proportionally there is a major presence of boosters in the subject area of Marketing (Table 1). More in particular, the amount of boosting elements in this area $(9,91)$ seems to double the quantity found in the discipline of Biology $(5,16)$ and the results in Mechanical Engineering $(4,16)$. These results match what could have been our initial expectations. Marketing is a fairly socially driven subject area that focuses on the habits and conventions of certain communities. The target of this discipline is generally to obtain patterns of behaviour that can influence the market of services or products. In this manner, Marketing becomes a rather social discipline. This feature results particularly important for use since it implies that the data implied within the research articles of this discipline will surely not be very numerical or precise, but rather based on speculations. It is so much so that this discipline is nurtured by other social sciences such as Psychology, Sociology or Anthropology. Consequently, and as it had been concluded before by other scholars, the nature of the science seems to strongly influence the use of interactional elements like boosters, in this particular case.

It could have been expected that the results of boosting elements in Mechanical Engineering research articles were practically inexistent. However, not only do they appear to be rather significant, but they also seem to be close to the results of research articles in the subject area of Biology. These findings result above all interesting due to the expectation created in the theoretical frame. According to certain theories regarding academic writing, authors in hard sciences did not seem to feel the need of using persuasive linguistic tools in their discourse. The reliable nature of the data used in the research should be evidential enough of the truth of the statements contained in the discourse. Mechanical Engineering involves the application of principles of physics for the analysis of its data. As a consequence and according to the hypothesis about hard sciences, there should hardly be any boosting elements in these randomly selected research articles. Nevertheless, the data in our analysis reveal a fairly considerable amount of boosting elements. This amount, in fact, surprisingly resembles the quantity of boosting elements found in the research articles belonging to the discipline of Biology. As mentioned above, the reason for the selection of Biology research articles is based on the nature of the target data used in its analysis is not blatantly numerical and precise, yet it is not based on abstract statements like in the case of social sciences. Biology spans everything: from disciplines such as chemistry or those centred on the study of molecules, where you get the mathematical data and use statistics, to the more "fuzzy" disciplines. For instance, evolutionary ecology may study an animal's mating behaviour. In this case, factors such as the chemistry, the environment, the development of the animal or even psychological factors may come into play. Biology is mainly focused on the study of the natural environment. Following with this pattern of behaviour, this concrete discipline uses data that are both numerical and not. As a consequence, and as it is reflected in the results found in our analysis, the amount of boosting elements locates this discipline in a rather middle point between the other two disciplines.

If we have a look at the rate of boosting elements used in each discipline (Figure 1), it becomes more evident that Marketing makes a much wider use of them than the other two disciplines. At the same time, we can observe the notable quantity contained in the discipline 
of Mechanical Engineering, despite some initial expectations regarding the reliable data used in its analysis.

In relation to the previous background theory that it seems to declare differences between soft and hard sciences, it could result easier to draw clearer conclusions with regards to the occurrence of boosters in such different disciplines as Marketing and Mechanical Engineering. It is clear that according to the results found in our analysis, there is a difference in the use of these interactional elements. For this reason, we will be taking into consideration the hypothesis made by those scholars who admitted the existence of different discourse and rhetoric features in hard and soft disciplines. These differences are mainly based upon the principle that hard sciences construct new knowledge from numerical, accurate data versus the more abstract nature of the data found in soft sciences.

\subsubsection{Boosters in Marketing}

The immediate interpretation of these findings suggests that scholars writing for the subject area of Marketing will generally expose their statements with a higher level of commitment and emphasis than those in the other disciplines. However, it is precisely this subject area the one that is supposed to be based on rather abstract data and, in consequence, not easily verifiable. The reasons behind the authors' decision of inserting boosters in their discourse are precisely related to this matter. Since Marketing statements are probably going to be more subject to the readership's interpretation, there is a stronger need to make those statements less subject to be negated. We have taken some samples of the research articles selected for our analysis in order to observe more clearly the functions of some of the most frequent boosters according to our calculations. Quote [1] has been withdrawn from the conclusions part. As we can observe, the author makes a fairly firm statement on what seems to be a recommendation. His intention seems to be the avoidance of alternative voices on what marketing managers should actually do. Instead of making a subtle recommendation, the author seems to be rather focused on the construction of new, concrete knowledge; knowledge that is as less subject to interpretation as possible. The main reason for the author's decision of inserting boosters in this particular case is closely related to the fact that there does not seem to be any accurate data supporting the statements. Therefore, the nature of the data appears to be designing the discourse in this particular example.

(1) Marketing managers must relate consumer needs and project development operations effectively if they are to succeed in developing new and profitable offerings in the marketplace. (Peters, 2001:23)

In example (2) we find that in his description of reality, the author starts his proposition preparing the readership to receive a true statement by placing indeed right at the beginning. This might be, again, due to the lack of certainty hidden in the nature of the data used for the analysis.

(2) Indeed, it is the hope of improvement in knowledge assimilation, organisational learning, 
and market focus that drives many modern organisations to establish corporate/client communication channels such as Intranets and Extranets. (Peters, 2004: 4).

In example (3), we can identify a similar function. The author is trying to convince the audience of the truth of the statement. He seems to be blocking any other viewpoints or stances that may rise in relation to the topic.

(3) Time has substantiated that this is not a fad and it certainly was not anticipated prior to the advent of Cigar Aficionado magazine. (Latour, 2003: 13)

In (4) the author similarly conveys a rather concrete description of reality. He parts from a committed statement to formulate another one. In this manner, the final statement appears to have been constructed from controlled variables and, therefore, appears to be more unarguable.

(4) Thus, communicators are in fact embedded within larger and more complex contexts and so these contexts must be understood when examining organisational communication. (Peters, 2004: 2).

In the following proposition, within example (5), we can observe that the author shows a clear involvement in its formulation. Unlike the previous example, this one derives from a statement presented in a way that is subtle to different stances on behalf of the readership. However, despite this, the author introduces the boosting element in order to achieve his final target. Even if the data are not very accurate, his intention is to convince the audience of his final conclusions. Consequently, he finds the need of making use of this persuasive element in his discourse.

(5) This would perhaps suggest that, for example, that 'Derived VC' is actually an extreme form of 'Net VC'; one where the consumer has discounted both sacrifice and attributes and, at the point of evaluation, is focusing purely on outcomes. (Woodhall, 2003: 15).

As we have seen, all these statements have been elaborated from a quite firm point of view. Even if the data are ambiguous or lacking numerical accuracy, scholars have presented these propositions with confidence. The underlying reasons for their acting are intimately related to rhetoric and persuasion. The only process capable of producing reliable statements in these areas seems to be through the use of persuasive linguistic devices, such as boosters. In this manner, new reliable knowledge is constructed within the discipline. Consequently, the subject areas are regarded as respectable sources of information.

\subsubsection{Boosters in Mechanical Engineering}

Mechanical Engineering is characterised by originating new knowledge originated from rather concrete, accurate data belonging, as a consequence, to the hard sciences. However, as the graph indicates, the use of boosting elements within this discipline is noticeable. 
Apparently, Mechanical Engineering still feels the need of inducting the audience to believe that what is being stated is true and, consequently, construct new knowledge within the discipline. As we have commented earlier in this work, every statement is actually subject to interpretation; even if it has been originated from exact calculations. Boosters are not so frequent in this discipline but they appear to strengthen their point of view. After all, absolute truths are not always possible.

According to some scholars who have studied interdisciplinary discourse and rhetoric, it would not be expected to find a great amount of boosting elements in such a hard science as Mechanical Engineering. Their reasons lie in the nature of the research data used in this kind of sciences, where the use of numerical data are so abundant. The immediate consequence of this feature, as we have commented earlier is that the data as such appear to become evidential enough of the truth of the statements accompanying them. However, examples (6) and (7) are only a sample of the fairly wide use of boosting elements in Mechanical Engineering, despite the expected reliability if their data derived from the analysis:

(6) The presented results demonstrate a model parameters influence on the relieved stress/strain response on the sample surface, thus on the computed calibration coefficients values as well. (Svantner, 2005: 11)

(7) The main steps of the long term analysis are shown in Figure 6. The inner iteration loop, the calculation of the stresses and strains are demonstrated in Figure 7. (Hegyi, 2004: 13)

In order to enhance the importance of the new knowledge introduced in the research article, authors make use of boosters to further increase the power of persuasion of what is being said. After all, their hypotheses, even if numerical and accurate, are subject to interpretation and must be defended from possible counter-hypothesis. In the following examples (8) and (9), we find that scholars have used the booster must to assure the truth of their propositions. In (9), we discover that the use of this booster is even triple.

(8) For the sake of further mathematical manipulations, we introduce the local numeration of nodes forming the arms of the star: $j=1 ; 2 ;: \therefore ; n$. For non-steady problems the time grid $\phi t$ must also be introduced:

$0=t 0<t 1<t 2<\because: \because f<t f+1<\because: 2<t F<1 ; \phi t=t f+1 ; t f$ “

(Mochnaki, 2005: 2)

(9) Any set of the above parameters allows the computation of a rod shape. First the helixform must be computed as an initial value problem from $s=0$ up to $s=s P$. Then the radial component of the inner forces must be modified by Q, and the system of differential equations of the closing loop must be solved until $\mathrm{s}=\mathrm{L}=4$. (Gaspar, 2005: 5)

We find the following instance of boosting in the conclusions part of one of the research articles selected for our analysis [10]. The author introduces the booster proved to describe the 
action he performs when carrying out his analysis. This shows that the author shows very much confidence in the truth of his propositions while is trying o suppress alternatives or perspectives on the topic of analysis.

(10) Using an approximate method for computing the twist and writhe of the spatial curve, we proved that the assumed configuration arises at very high twist rates beyond the interests of former research work. (Gaspar, 2005: 14)

In this manner, the scholar gains reputation and reliability by convincing the audience of the truth of his statements. Let us not forget that the fact that that data used for his research are perhaps more precise and accurate for belonging to the hard sciences category, seems to facilitate the certainty authors can or may show in their discourse. However, the final purpose of their use is both the same for soft and hard sciences: to persuade the audience and convince it of the truth of what is being stated in the article.

As a conclusion, we will comment that the percentage of boosters in Marketing practically doubles Mechanical Engineering ( 0.99 versus 0.41 ), which proves the different nature of the data used for each analysis in the disciplines.

\subsubsection{Boosters in Biology}

In order to reach the conclusions drawn for Marketing and Mechanical Engineering we had to pay attention to the nature of the data used in their researches. Therefore, it seems rather logical to start with the analysis of interactional elements in this discipline having a closer look at the nature of Biology data in research articles. As it has been commented before in this paper, Biology could be regarded as a complex subject area where different disciplines come into play. Not only disciplines where accurate data are frequent, such as Mathematics, Chemistry or Physics are important for the development of this area. Other more Humanistic disciplines play an equally important role for the analysis of issues concerning this area. Such is the case of psychological factors or Sociology (particularly in the example of Zoology), or even inaccurate data derived from phenomena that seem to be still nowadays unable to calculate accurately. Such is the case of weather phenomena or other issues that depend on random factors and many agents impossible to control at least in a long term period.

In the five randomly selected examples in the discipline of Biology, we have found diversity of functions according to the nature of the nature of the data involved in each instance.

In example (11), the accuracy of the data belonging to the records allows the author to introduce the first token ("always 20 slower"). This appearance acts in his favour since the second statement makes reference to his own hypothesis. However the nature of this second data does not appear to be as exact and reliable as in the first instance. The author, therefore, makes use of this second token with a different purpose this time. Since he has already based his hypotheses on a safe ground thanks to the first token, the second statement should be expected to result equally accepted as true. However, Anthropology, as a social science, is not so accurate as to be able to affirm such statements. The nature of its data are subject to random variations and although some could be predicted, not all factors influencing the final results 
are under control. For this reason, the author feels the need to use this second token to reassure the truth in the proposition.

(11) Natural changes in atmospheric CO2 over the past 650000 years as recorded in Antarctic ice core records (Petit et al., 1999; Siegenthaler et al., 2005) were always 20 slower and smaller in amplitude than the anthropogenic impact of the last 250 years. Therefore it is conservative to assume that the oceanic uptake of a terrestrial disturbance in the past will always be greater than during the anthropogenic period. (Köhler, 2006: 17)

Example (12) appears to be a clear token conveying involvement on behalf of the author at the same time as some amount of uncertainty. Whereas the author is making reference to an empirical method for the analysis of data, his statement is no other than a mere hypothesis. Therefore, in this particular case, we will be talking, again, about reassurance and enhancement of the truth of a proposition that is perfectly subject to interpretations and that could easily be negated by other scholar in the discipline with a different perspective on the topic in question.

(12) We believe from our analysis that the processes responsible for these variations can not be identified based on a Keeling plot analysis. (Köhler, 2006: 35)

We notice in example (13) that the nature of the data influencing the statements are of a different nature than in the previous cases. Whereas in the examples above we could be dealing with rather abstract data, in this case we find that the origins of the proposition containing "shown" derives from what seems to be the results of almost undeniable chemical analysis. For this reason, we describe the function of this boosting element as playing a role related to the persuasion of the audience into a state of absolute certainty that what is being stated cannot be rejected as absolute true. On the other hand, due to the lack of absolute truths and also the presence of such a competitive market as far as research is concerned, the author has preferred to introduce a boosting element in order to reassure his statement.

(13) It has also been shown that blockade of co-stimulation prevented allergen-induced chemotaxis, as well as secretion of IL-16 and RANTES in bronchial biopsy tissue obtained from asthmatics (22). (Burr et al., 2001: 5)

Example (14) within the discipline of Biology derives again from numerical data noticeably less subject to be interpreted differently to the author's remarks. Consequently, the author shows a high level of commitment with his proposition (also noticeable with the addition of the intensifier well). In this case, we can talk again about further reassurance. The audience in these cases does not really need to be persuaded; they are cases where the author merely reaffirms the content in his propositions showing more involvement highlighting the amount of objectivity contained in them. The same happens in the second token handling with reliable data as well. 
(14) As is well established from observations (e.g. WMO, 2002, Chapter 3), polar ozone has been decreasing over this time frame. Figure 9 shows the minimum daily ozone throughout the latitudes $60 \_-90_{-} \mathrm{N}$ for the range of models of Table 1 together with TOMS data. (Austin et al., 2003: 18)

In (15) we can observe the ambiguity of the data related to the conclusions drawn by the author. It is precisely for this reason that the author needs to make use of a boosting element that reaffirms this uncertainty.

(15) The CCSR/NIES results are somewhat smaller for the future, as indicated above, and in addition to the large errors these results suggest that extrapolation of the current observed trends to the future must remain uncertain. (Austin et al., 2003:17)

Our first observations after the analysis of boosting elements in this discipline are focused on the different types of data contained in this subject area. Not only can we find numerical data that result more reliable in the analysis results, but also more abstract hypothesis from which conclusions are equally drawn. The figures in Table 1 reveal a medium position of this discipline regarding the use of boosters. However, it does not lack logical reasoning if we take into consideration the data used in the research of this discipline. Whereas on the one hand, it makes use of numerical, reliable data that should not need of much enhancement for the reassurance of its truth, on the other hand, there are other variables affecting the final outcome of the analysis. These factors belong to Humanistic disciplines, as we have already commented earlier. In these concrete examples, we can observe the influence of these variables in examples (2), (3) and (6). Alternatively, the wide use of numerical data present in our selected articles of Biology make a strong influence in the fact that this discipline is closer to the results found in Mechanical Engineering. On the whole, we can affirm that the nature of the data present in research articles will become the keystone regarding the amount of boosting elements appearing in them.

\section{Conclusions and final remarks}

Academic writing has the main purpose of spreading new knowledge and discussing old. Rhetoric becomes, thus, fundamental in the construction of this genre since it strongly contributes to a successful dialogic negotiation of knowledge. In addition, rhetoric strategies also become key in the supporting argumentation behind new statements presented in the research articles. Furthermore, it is inevitable that during this process authors wish to promote themselves. In doing so, they will also defend the statements present in their texts thanks to rhetorical strategies. Against to some claims made by scholars, supporting the idea that academic writing should always remain as objective and neutral as possible, academic writing very often seeks to demonstrate a viewpoint based on scientific research in the detriment of another one. Interactional elements such as boosters strongly contribute to the consecution of these purposes. Boosters show the amount of the author's commitment with what is being 
stated in his/her propositions. This immediately produces engagement and complicity on the readership.

Our analysis of boosting in different disciplines has revealed that not only there are differences in occurrence of boosters and hedges in the RAs selected but we believe that these differences also depend on the nature of the data used for the research in each discipline. Each discipline tries to fulfil social needs in different areas. The sociological features of each discipline may be shaping the discourse in their RAs differently. This appears reflected in the presence of these interactional elements.

With reference to Marketing, the discipline selected to represent soft sciences, it is a discipline that bases its statements from observing patterns of human behaviour. The data are, therefore, rather inexact. In consequence, the need for creating more solid statements and certainty is stronger than in harder sciences. For this reason, boosters appear at a greater frequency than in other disciplines here analyzed. Through the use of these persuasive linguistic devices, new statements gain strength. New knowledge appears to be more reliable engaging the reader's responses and the text is more subject to be respected as a valid source of information within the discipline.

The results of boosting in Mechanical Engineering appear to be different from our initial expectations. Although the number of booster elements is very low, it is also true that it is worth considering due to the initial hypothesis our background theory had set. It is evident that Mechanical Engineering belongs to the category of hard sciences. The data handled within this discipline is closely related to subject areas such as Mathematics or Physics. In consequence, the data involved in the analysis and research of Mechanical Engineering is going to be more precise and accurate than in the case of Marketing or other soft sciences. In addition, according to some rhetorical theories concerning academic writing, some scholars, like Booth (1985), Bazerman (1984) or Bolsky (1988), claim that this kind of writing should stay aseptic and as objective as possible avoiding all sorts of ambiguous propositions. After all, the readership turns to this source of information to provide itself with accurate knowledge on the subject area in question. On this basis, we should not expect the presence of boosting elements that convey power of persuasion and conviction to the statements. In the case of hard sciences, the data itself was initially supposed to provide the readership with enough evidence that what is being stated can be perfectly considered as reliable truth. Yet, there is still a significant presence of boosting elements in the RAs analyzed. Although the accurate data of this discipline may result assertive enough and produce an effect of engagement on the readership by itself, we must also consider that there does not seem to be absolute truths. Everything seems to be subject to be interpreted from different perspectives. In fact, hard sciences construct new knowledge parting from the negation of statements derived from accurate data. In consequence, boosters contribute to the assurance of new statements in defence of the author's work.

The analysis in Biology research articles shows that the presence of boosters is moderate in comparison to Marketing and Mechanical Engineering research articles. The nature of this discipline is of particular importance since it could also be considered to be in between Marketing and Mechanical Engineering. Biology entails different subject areas such as Psychology, Anthropology, Mathematics, Chemistry or Geology. In consequence, the data 
resulting from biological research will be a combination of both accurate and abstract data. Boosters will express confidence in the truth of propositions in relation to data and/or facts that are more subject to the readership's interpretation. In the same manner, boosters will also play the role of persuasion concerning this kind of data contained in the biological research.

Different disciplines deal with different data and hence, show different amounts of boosters in their discourse. In this way, we can talk about different rhetorical patterns in the construction of information as regards disciplinary variation. On the whole, we can talk about different social needs constructing different disciplines. Whereas softer sciences seem to present a stronger need for enhancing the propositional content in the containing statements, harder sciences rely on the exactness of the data used in their research as sufficiently evidential to show the truth of their statements. Boosters will still act as persuasion devices for the discourse. In this manner, boosters will reassure the information conveyed in order to suppress possible alternatives convincing the readership of the truth of the statements.

\section{Notes}

1. See www.interlae.com

\section{References}

Bazerman, Charles (1984): "Modern Evolution of the Experimental Report in Physics. Spectroscopic Articles in Physical Review, 1893-1980”. Social Studies of Science 14: 163-193.

Beauvais Paul (1989): "A speech act theory of metadiscourse". Written Communication 6: 11-30. Bolsky, Morris (1988): Better Scientific and Technical Writing. Englewood Cliffs, NJ: Prentice-Hall. Booth, Vernon (1985): Communication in Science: Writing and Speaking. Cambridge: Cambridge University Press.

Bowman Edward (1984): "Content analysis of annual reports for corporate strategy and risk". Interfaces 14: 61-71

Brent Douglas (1985): "Indirect Structure and Reader Response". The Journal of Business Communication 22: 5-8.

Brown Gillian and Yule George (1983): Discourse Analysis. Cambridge: Cambridge University Press.

Brown Penelope and Levinson Stephen (1978): "Universals in language usage: Politeness phenomena". In E. Goody, ed., Questions and Politeness: Strategies in Social Interaction. Cambridge: Cambridge University Press, 56-310.

Campbell Kim Sydow (1990): "Explanations in negative messages: More insights from speech act theory". The Journal of Business Communication 27: 357-375.

Channell Joanna (1994): Vague Language. Oxford: Oxford University Press.

Clemen Gudrun (1997): “The concept of hedging: origins, approaches and definitions". In Markkanen and Schröder, eds., 235-248.

Crismore Avon and Farnsworth Rodney (1990): "Metadiscourse in popular and professional science discourse". In W. Nash, ed., The Writing Scholar: Studies in Academic Discourse. Newbury Park, CA: Sage, 118-136.

Crismore Avon and Vande Kopple William (1988): "Readers' learning from prose: The effects of hedges”. Written Communication 5: 184-202. 
. (1997): "Hedges and readers: effects on attitudes and learning". In Markkanen and Schröder, eds., 83-114.

Crismore Avon, Markkanen Raija and Steffensen Margaret (1993): "Metadiscourse in persuasive writing: A study of texts written by American and Finnish university students". Written Communication 10: 39-71.

Crompton Peter (1997): "Hedging in academic writing: Some theoretical problems". English for Specific Purposes 16: 271-287.

Dafouz-Milne Emma (2008): "The pragmatic role of textual and interpersonal metadiscourse markers in the construction and attainment of persuasion: A cross-linguistic study of newspaper discourse". Journal of Pragmatics 40: 95-113.

Dahl Trine (2004): "Textual metadiscourse in research articles: A marker of national culture or of academic discipline?" Journal of Pragmatics 36: 1807-1825.

Fuertes-Olivera, Pedro; Marisol Velasco-Sacristán; Ascensión Arribas Baño and Eva Samaniego Fernández (2001): "Persuasion and Advertising English: Metadiscourse in Slogans and headlines". Journal of Pragmatics 33: 1291-1307.

Grabe William and Robert B. Kaplan. (1997): "On the writing of science and the science of writing: Hedging in science text and elsewhere". In Markkanen and Schröder, eds., 151-167.

Holmes Janet (1982): "Expressing doubt and certainty in English". RELC Journal 3: 9-28.

Hübler Axel (1983): Understatements and Hedges in English. Amsterdam: John Benjamins.

Hyland Ken (1994): "Hedging in academic writing and EAP textbooks". English for Specific Purposes 13: $239-256$.

. (1996): "Talking to the academy: Forms of hedging in science research articles". Written Communication 3: 251-281. 349-382.

. (1998a): "Boosting, hedging and the negotiation of academic knowledge". Text 18:

. (1998b): "Exploring corporate rhetoric: Metadiscourse in the CEO's setter". The Journal of Business Communication 35: 224-245.

. (1998c): "Hedging in Scientific Research Articles". Amsterdam: John Benjamins Publishing Company.

. (1998d): "Persuasion and context: The pragmatics of academic metadiscourse". Journal of Pragmatics 30: 437-455.

. (1999): "Talking to students: Metadiscourse in introductory coursebooks". English for Specific Purposes 18: 3-26.

. (2001): "Humble servants of the discipline? Self-mention in research articles". English for Specific Purposes 20: 207-226.

. (2004): Disciplinary Discourses: Social Interactions in Academic Writing. Ann Arbor: The University of Michigan Press.

. (2005): Metadiscourse. London: Continuum.

Ifantidou Elly (2005): "The semantics and pragmatics of metadiscourse". Journal of Pragmatics 37: $1325-1353$.

Koutsantoni Dimitra (2006): "Rhetorical strategies in engineering research articles and research theses: Advanced academic literacy and relations of power". Journal of English for Academic Purposes 5: 19-36.

Kuo Chih-Hua (1999): "The use of personal pronouns: Role relationships in scientific journal articles". English for Specific Purposes 18: 121-138.

Markkanen Raija and Schröder Hartmut (eds.) (1997): Hedging and Discourse: Approaches to the Analysis of a Pragmatic Phenomenon in Academic Texts. Berlin: Walter de Gruyter. 
Mauranen Anna (1993): "Contrastive ESP rhetoric: Metatext in Finnish-English economics texts". English for Specific Purposes 12: 3-22.

Myers Greg (1989): “The pragmatics of politeness in scientific articles”. Applied Linguistics 10: 1-35.

Varttala Teppo (1999): "Remarks on the communicative functions of hedging in popular scientific and specialist research articles on medicine". English for Specific Purposes 18: 177-200.

Vassileva Irena (2001): "Commitment and detachment in English and Bulgarian academic writing". English for Specific Purposes 20: 83-102.

Vázquez Ignacio and Diana Giner (2008): "Beyond Mood and Modality: Epistemic Modality markers as hedges in Research Articles. A cross-disciplinary study". Revista Alicantina de Estudios Ingleses 21:171-190. 